\title{
PELATIHAN PERSIAPAN MEMASUKI MASA PUBERTAS BAGI SISWA SEKOLAH DASAR NEGERI 69 KOTA BENGKULU
}

\section{TRAINING PREPARATION FOR ENTERING PUBERTY AGE FOR STUDENTS OF ELEMENTARY SCHOOL 69 BENGKULU CITY}

\author{
Oleh: \\ Rita Sinthia, Mona Ardina, dan Yessy Elita \\ Fakultas Keguruan dan Ilmu Pendidikan Universitas Bengkulu \\ sinthia.rita@yahoo.com,mona.ardina@gmail.com,yessyelita@gmail.com
}

\begin{abstract}
This activity was conducted to prepare elementary school students, particularly the fifth and sixth grade students of SDN 69 Kota Bengkulu in entering puberty period. Puberty is the period development during, when the children from being regarded as asexual creatures to being extremely sexual. The experience of puberty period of children is characterized by primary sex characteristics, where the girls will experience first menstruation period. While some boys experience wet dream. According the result of observation and interview towards students, many students could not figure out what puberty is. The data show that the students do not acquire enough knowledge about what they will experience in puberty period. It may causes the students create poor attitude toward puberty period such as; shock even depressed and profoundly ashamed. That's why the students need guide in aware puberty period in order to be able to face puberty period in physical change as well as emotional change. This activity was participated by 43 students. The method of this research was lecture and fun discussion. The result of this activity shows that the students have understanding of puberty, and they are supposed to be able to know how to deal with puberty period, thus they are able to do the development tasks in this stage as it should be.
\end{abstract}

Keywords: preparation, puberty, elementary school students

\section{PENDAHULUAN}

Perkembangan manusia dimulai dari masa pembuahan atau konsepsi dan berlangsung sepanjang rentang kehidupan manusia, yang terbagi dalam beberapa fase perkembangan. Perkembangan anak terbagi menjadi 2 fase, yaitu masa kanak-kanak awal dan masa kanak-kanak akhir. Pada masa kanak-kanak akhir, banyak tugas perkembangan yang harus dikuasai dan dicapai oleh seorang anak. Salah satunya adalah mempersiapkan masa pubertas yang terjadi di akhir masa kanak-kanak menjelang masa remaja.

Pubertas menurut Hurlock (2010) adalah periode dalam rentang perkembangan ketika anak-anak dari makhluk aseksual menjadi makhluk seksual. Masa pubertas juga merupakan masa perkembangan yang akan dilalui setiap individu setelah melewati masa anak-anak akhir. Seorang anak tentunya akan selalu menghadapi masa pubertas ketika anak tersebut telah memasuki usia tertentu. Fase ini dimulai dari usia 9/10 tahun untuk anak perempuan atau 13/16 tahun untuk anak laki-laki. Ketika memasuki masa puber ada beberapa perubahan yang akan dialami anak baik dalam hal fisik maupun psikologis. Tanda anak mengalami masa pubertas ditandai oleh ciri kelamin primer, dimana anak 
perempuan mengalami haid untuk pertama kali. Sedangkan pada anak laki-laki ditandai dengan mimpi basah.

Berdasarkan hasil observasi dan wawancara dengan siswa, banyak siswa yang belum mengerti apa itu pubertas. Data menunjukkan bahwa jika anak tidak mendapat pengetahuan yang cukup mengenai apa yang akan dialaminya dalam masa pubertas, maka akan membuat anak kaget bahkan depresi serta rasa malu yang berlebihan. Hal ini akan berdampak pada rasa percaya dirinya. Dimana masa remaja merupakan masa mencari identitas. Jika anak tidak mendapatkan bimbingan akan membuat anak menjadi salah jalan. Untuk itulah diperlukan bimbingan bagi anak untuk menghadapi masa pubertas agar anak menghadapi masa puber dengan lebih baik dari segi emosional maupun dari segi fisiknya. Di masyarakat sendiri masih banyak orang tua yang tidak pernah mempersiapkan anaknya untuk memasuki fase ini. Para orangtua masih menganggap tabu untuk membicarakan masalah ini. Sehingga banyak anak-anak yang tidak mengerti akan perubahan yang terjadi pada dirinya. Hal ini dapat menyebabkan anak mendapat informasi yang salah dari pihakpihak yang tidak bertanggung jawab dan akan berdampak kepada kehidupan sosial dan emosionalnya di kemudian hari. Sebagaimana kita ketahui bersama anak adalah aset bangsa. Perlu dan penting bagi kita sebagai orang dewasa yang memiliki pengetahuan dan keterampilan tentang hal ini, untuk mempersiapkan anak menghadapi masa pubertas.

Berdasarkan latar belakang permasalahan yang telah diuraikan maka dapat dirumuskan permasalahan dalam kegiatan ini adalah: Bagaimana memberikan pengetahuan tentang masa pubertas kepada anak sekolah dasar khususnya kelas 4 dan 5 ?

Pubertas yang dahulu dianggap sebagai tanda awal keremajaan ternyata tidak lagi valid sebagai patokan atau batasan untuk pengkategorian remaja sebab usia pubertas kini terjadi pada awal belasan bahkan sebelum usia 11 tahun (Hurlock, 2010). Seorang anak berusia 10 tahun mungkin saja sudah (atau sedang) mengalami pubertas namun tidak berarti anak tersebut sudah bisa dikatakan sebagai remaja dan sudah siap menghadapi dunia orang dewasa. Dalam perkembangannya seringkali anak-anak usia pubertas menjadi bingung, karena kadang-kadang diperlakukan sebagai anak-anak tetapi di lain waktu dituntut untuk bersikap mandiri dan dewasa.

Pengertian pubertas (Santrock, 2002) adalah masa ketika seorang anak mengalami perubahan fisik, psikis, dan pematangan fungsi seksual. Masa pubertas dalam kehidupan kita biasanya dimulai saat berumur delapan hingga sepuluh tahun dan berakhir lebih kurang di usia 15 hingga 16 tahun. Masa pubertas merupakan permulaan berfungsinya organ reproduksi yang diiringi berbagai perubahan fisik dan kejiwaan (mental), baik dalam skala eksternal maupun internal. Sejalan dengan perkembangan fisiknya, pada masa remaja juga akan terlihat jelas berbagai perubahan yang menyangkut aspek psikis, sosial dan perilakunya.

Pada saat seorang anak memasuki masa pubertas yang ditandai dengan menstruasi pertama pada anak perempuan atau pun mimpi basah pada anak laki-laki, secara biologis anak-anak tersebut mengalami perubahan yang sangat besar (Jess dan Gregory, 2008). Pubertas menjadikan seorang anak tiba-tiba memiliki kemampuan untuk ber-reproduksi. Pada masa pubertas, hormon seseorang menjadi aktif. Pertumbuhan secara cepat dari hormon-hormon tersebut di atas merubah sistem biologis seorang anak terutama pada anak perempuan. Anak perempuan akan mendapat menstruasi, tumbuhnya bulu-bulu halus di daerah tertentu, pembesaran buah dada, dan lain sebagainya sebagai pertanda bahwa sistem reproduksinya sudah aktif (Sunarto dan Hartono, 2013). Bentuk fisik anak-anak akan berubah secara cepat sejak awal pubertas dan akan membawanya pada dunia remaja. Disamping itu, perubahan fisik tersebut akan mempengaruhi pula keadaan psikis, kognitif, 
dan sosial anak. Ketidaknyamanan pada tubuh yang dirasakannya, dan ketidakpahaman anak dalam menghadapi perubahan tersebut akan menimbulkan perilaku-perilaku baru seperti menjadi mudah marah, melawan, bingung, berperilaku yang beresiko, eksperimen terhadap zat, problem sekolah, keluhan psikosomatis, aktivitas seksual, dan lain sebagainya.

Masa puber terjadi secara bertahap, yaitu: (Hurlock, 2010).

1. Tahap Pra-pubertas

Tahap ini disebut juga tahap pematangan yaitu pada satu atau dua terakhir masa kanak-kanak. Pada tahap ini, anak dianggap sebagai prapuber, sehingga ia tidak disebut seorang anak dan tidak pula seorang remaja. Pada tahap ini, ciri-ciri seks sekunder mulai tampak namun organ-organ reproduksinya belum berkembang secara sempurna.

2. Tahap Puber

Tahap ini disebut juga tahap matang, yaitu terjadi pada garis antara masa kanakkanak dan masa remaja. Pada tahap ini, kriteria kematangan seksual mulai muncul. Pada anak perempuan terjadi haid pertama dan pada anak laki-laki terjadi mimpi basah pertama kali, serta mulai berkembang ciri-ciri seks sekunder dan sel-sel diproduksi dalam organorgan seks.

3. Tahap Pasca puber

Pada tahap ini menyatu dengan tahun pertama dan kedua masa remaja. Pada tahap ini, ciri-ciri seks sekunder sudah berkembang dengan baik dan organ-organ seks juga berfungsi secara matang.

Apa yang terjadi waktu puber? Waktu tubuh siap untuk puber, kelenjar kecil di bawah otak yang bernama kelenjar pituitary akan mengeluarkan 2 (dua) hormon yaitu :

1) Hormon pertumbuhan yang membuat tubuh kita tinggi dan besar, yang pastinya masing-masing anak tumbuh dengan berbeda-beda karena perbedaan gizi dan faktor keturunan.

2) Hormon gonadotrofik yang akan menyuruh organ reproduksi menghasilkan hormon testosteron dan estrogen.

a. Tubuh anak laki-laki akan menghasilkan hormon testosteron yang akan membuat alat reproduksinya menjadi lebih besar serta memproduksi sperma. Selain itu biasanya akan muncul bulu-bulu halus di daerah sekitar penis, ketiak, kaki, dan wajah. Suara anak laki-laki juga menjadi lebih dalam dan muncul jakun di leher. Anak laki-laki juga akan lebih banyak berkeringat dan baunya lebih khas, kulit menjadi lebih berminyak dan menyebabkan munculnya jerawat. Payudara anak laki-laki juga seperti tumbuh, akan tetapi biasanya akan hilang dengan sendirinya 1-2 tahun setelahnya. Selain perubahan fisik, anak laki-laki juga mengalami mimpi basah. Mimpi basah adalah proses ejakulasi alami yang terjadi karena penuhnya kantung testis oleh sperma sehingga tubuh mengeluarkan cairan sperma dan sperma yang ada di dalamnya ketika tidur. Anak tidak perlu malu dan merasa bersalah karena mimpi basah merupakan hal biasa yang terjadi pada anak laki-laki dan tidak bisa dikendalikan. Cairan sperma dan sperma yang tidak dikeluarkan dari tubuh akan diserap kembali oleh tubuh dan akan dikeluarkan lewat keringat.

b. Tubuh anak perempuan akan menghasilkan hormon estrogen yang membuat organ reproduksinya menjadi lebih besar dan sel telur yang di dalam organ anak perempuan mulai menjadi matang. Sel telur yang sudah matang akan dilepaskan satu per satu dalam proses yang disebut ovulasi. Sebelum terjadi ovulasi, dinding uterus atau biasa disebut rahim akan membuat lapisan tebal, bersiap menghadapi kemungkinan terjadinya pembuahan. Jika ternyata sel telur tidak dibuahi, tubuh 
akan mengirim sinyal bahwa sel telur sudah tidak dibutuhkan. Sel telur larut bersama lapisan dinding uterus dan dikeluarkan dari vagina. Hal ini yang disebut dengan menstruasi/haid

Tanda-tanda datangnya menstruasi:

a) Payudara membengkak dan terasa nyeri

b) Kembung, kram di kaki, punggung atau perut

c) Berjerawat

d) Muncul perasaan tegang, cemas, murung

Tanda-tanda tersebut disebut gejala Pra-Menstruasi (PMS). Hal tersebut wajar karena kadar hormon akan naik turun.

Adapun tujuan kegiatan PPM ini adalah:

1. Memberikan pengetahuan mengenai masa pubertas dan persiapan menghadapinya kepada anak sekolah dasar khususnya kelas 4 dan 5.

2. Memberikan pendampingan kepada anak sekolah dasar khususnya kelas 4 dan 5 .

Diharapkan kegiatan PPM ini dapat memberikan manfaat, antara lain:

1. Manfaat bagi anak

a. Anak memiliki pengetahuan mengenai proses perkembangan yang akan dialaminya

b. Anak memahami dan mengetahui perilaku-perilaku yang memadai ketika mengalami pubertas

2. Manfaat bagi tim pelaksana

Pengalaman ini diharapkan dapat memberikan pengalaman berinteraksi langsung dengan siswa sekolah dasar sehingga mampu merumuskan solusi yang lebih baik untuk membantu siswa dalam menghadapi masa pubertas.

3. Manfaat bagi institusi

Melalui kegiatan ini diharapkan dapat terjalin kerjasama lebih baik antara Universitas Bengkulu dan SD Negeri 69 Kota Bengkulu, sehingga dapat memberikan kontribusi positif pada kedua pihak.

\section{METODE PENGABDIAN}

Kegiatan pengabdian kepada masyarakat ini dilaksanakan pada hari Sabtu, tanggal 12 Agustus 2017. Bertempat di SD Negeri 69 Kota Bengkulu. Jumlah peserta sebanyak 43 orang siswi, dan 6 orang mahasiwi Prodi Bimbingan Konseling yang bertugas sebagai fasilitator dan tim kegiatan pengabdian kepada masyarakat.

Adapun tahapan pelaksanaan kegiatan pengabdian kepada masyarakat ini adalah sebagai berikut :

1. Langkah 1 (Metode Ceramah). Pada awal kegiatan peserta diberi tes yang berisi sejumlah daftar pertanyaan yang berhubungan dengan masa pubertas. Tujuannya untuk mengetahui tingkat pemahaman peserta tentang masa pubertas sebelum diberikan materi. Selanjutya peserta pelatihan diberikan materi tentang "Kesehatan Reproduksi" dan "Masa Pubertas dan persiapan menghadapinya" yang diselenggarakan melalui metode ceramah selama 1,5 jam. Agar peserta tertarik dan tidak bosan, maka materi diberikan secara menyenangkan dan diselingi dengan permainan, seperti ice breaking dan melihat tayangan video tentang memasuki masa pubertas

2. Langkah 2 (Metode fun discussion). Kegiatan ini siswa didampingi oleh fasilitator (mahasiswa Prodi Bimbingan Konseling FKIP Universitas Bengkulu) untuk memberikan penguatan tentang masa pubertas. Penguatan ini dilakukan dengan 
bimbingan kelompok dan diskusi untuk mengetahui tingkat pemahaman peserta setelah diberikan materi. Pada akhir kegiatan peserta diberi tes yang sama seperti yang diberikan sebelum kegiatan dimulai.

\section{HASIL DAN PEMBAHASAN}

Berdasarkan hasil kegiatan yang dilakukan terdapat peningkatan pemahaman anak tentang masa pubertas. Hal ini terlihat dari hasil pretest dan posttest yang diberikan oleh tim kegiatan pengabdian. Sebelum kegiatan dilakukan siswa diberikan tes yang berisi sejumlah daftar pertanyaan yang berhubungan dengan masa pubertas. Dari 43 orang siswa yang mengisi terdapat 10 orang siswa yang pernah mendengar istilah pubertas karena sebagian anak yang telah mengetahui tentang pubertas telah mengalami menstruasi. Selebihnya, 33 orang siswa belum mengetahui apa itu pubertas, apa yang akan terjadi jika anak berada pada masa pubertas, apa yang harus anak lakukan jika berada pada masa pubertas. Setelah diberi pemahaman melalui metode ceramah dan menonton video, siswa mulai memiliki pengetahuan dan memahami mengenai pubertas.

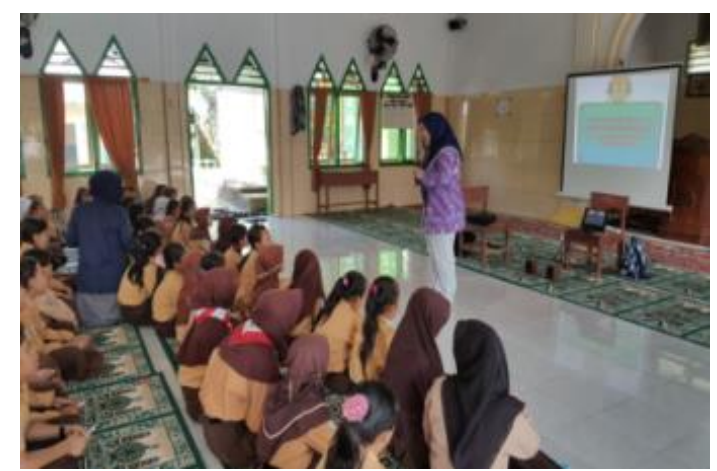

Gambar 1. Kegiatan ceramah

Selanjutnya untuk melihat sejauh mana pemahaman siswa tentang masa pubertas, diberikan kegiatan bimbingan kelompok yang bertujuan untuk menyamakan persepsi tentang masa pubertas.

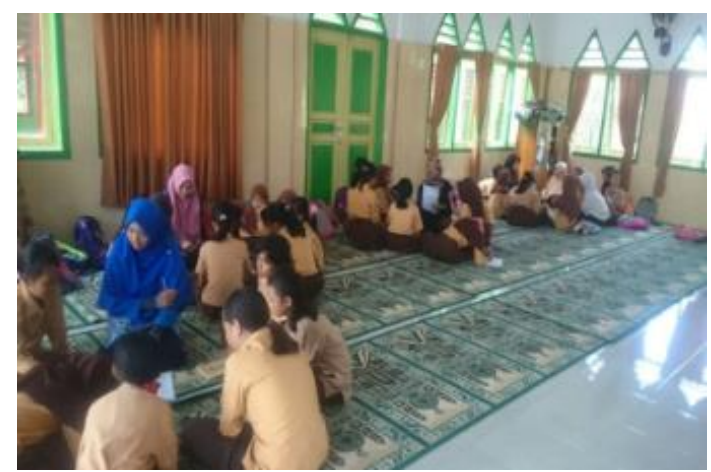

Gambar 2. Kegiatan bimbingan kelompok

Menurut Hurlock (2010) jika anak mampu mengenal dirinya, anak akan tumbuh menjadi anak yang percaya diri, tidak akan mengalami hambatan atau gangguan dalam menghadapi tugas-tugas perkembangannya. Tugas perkembangan remaja yang harus dilalui adalah sebagai berikut: 
1. Mencapai hubungan baru yang lebih matang dengan teman sebaya baik pria maupun wanita.

2. Mencapai peran sosial pria dan wanita.

3. Menerima fisiknya dan menggunakan tubuhnya secara efektif.

4. Mengharapkan dan mencapai perilaku sosial yang bertanggung jawab.

5. Mempersiapkan karir ekonomi.

6. Mempersiapkan perkawinan keluarga.

7. Memperoleh perangkat nilai dan sistem etis sebagai pegangan untuk berperilaku mengembangkan ideologi.

\section{KESIMPULAN DAN SARAN}

\section{Kesimpulan}

Berdasarkan hasil observasi dapat disimpulkan:

1. Sebanyak $80 \%$ siswa sudah mengerti dan memahami tentang masa pubertas.

2. Siswa sudah tahu apa yang harus dilakukan ketika memasuki masa pubertas.

3. Siswa mampu mengenali emosi-emosi yang ada ketika berada pada masa pubertas.

\section{Saran}

Adapun saran dari kegiatan ini adalah:

1. Perlunya bimbingan dan pengawasan dari orangtua dan guru ketika anak memasuki masa pubertas

2. Orang tua dan guru dapat bekerjasama untuk membantu anak dalam mengisi waktu luang dengan mengikuti kegiatan yang positif dan bermanfaat seperti ekstrakulikuler yang ada di sekolah.

\section{DAFTAR PUSTAKA}

Hurlock, E.B, 2010, Psikologi Perkembangan. Suatu Pendekatan Sepanjang Rentang Kehidupan (terjemahan), Alih Bahasa: Istiwidayanti dan Soedjarwo, Erlangga, Jakarta.

Jess, Feist dan Gregory J.F, 2008, Theory of Personality: Edisi keenam (terjemahan), Pustaka Belajar, Yogyakarta.

Nurihsan, A.J dan Agustin M, 2011, Dinamika Perkembangan Anak dan Remaja, Refika Aditama, Bandung.

Santrock, 2002, Life-Span Development, Perkembangan Masa Hidup (terjemahan), Erlangga, Jakarta.

Sunarto dan Hartono, 2013, Perkembangan Peserta Didik, Rineka Cipta, Jakarta. 